\title{
The Effectiveness of Coping Strategy Training For Behavioural Modification among School Going Heart Defect Children after Surgery
}

\author{
Mridula. C. Jobson ${ }^{1} *$, Dr. R. Subhashini ${ }^{2}$
}

\section{ABSTRACT}

The Congenital heart disease -CHD has come to be regarded as a chronic rather than terminal disease owing to dramatic advances in its medico surgical management paving the emerging recognition of behavior problem in children Thus, it is salient for healthcare providers to help children with CHD increase their resilience by using effective coping strategies. In the process of growing, middle child hood experience stress so called unexplainable emotion reflecting in behavior modification and the improvement outcomes depends upon on how they cope. It is noteworthy that persistent over stress will impair students’ academic achievement, interpersonal and intra personal development. This preliminary study is meant to obtain the effectiveness of coping strategies training among middle school children who have undergone heart defect surgery rejoining school after a break due to hospitalization. The objective is to examine the comparison between coping strategies trained (CST) CHD and coping strategy untrained (CSUT) CHD children. An experimental study involved 20 surgically operated CHD middle school children. The samples selected using simple randomized sampling which was divided into 2 groups ExperimentalGroup1 CST, ControlGroup2: Control group CSUT. A validated Coping Strategies Inventory (CSI) by Davidl. Tobin's 72-itemQuestionnaire was used to assess coping thoughts and behaviors in response to a specific stressor .Highly significant coping skill was found in group1 who underwent CST .The CST trained children showed a positive approach towards their phase of life after complicated heart surgery.

Keywords: Stress, Behavior, Coping Strategies, Middle School Children, Congenital heart defect.

\footnotetext{
${ }^{1}$ Research Scholar; Mother Teresa University Kodaikanal; Lecturer- MMM College of Health Sciences.Chennai; Tamilnadu, India

${ }^{2}$ Dean and HOD - Department of Counseling Psychology; Madras School of Social Work. Chennai; Tamilnadu, India

*Responding Author

(C) 2016, M Jobson, R Subhashini; licensee IJIP. This is an Open Access Research distributed under the terms of the Creative Commons Attribution License (http://creativecommons.org/licenses/by/2.0), which permits unrestricted use, distribution, and reproduction in any Medium, provided the original work is properly cited.
} 


\section{The Effectiveness of Coping Strategy Training For Behavioural Modification among School Going Heart Defect Children after Surgery}

Congenital Heart Disease (CHD) or Congenital Heart anomaly is a defect in the structures of the heart and great vessels which is present at birth. The causes for CHD are genetic and environmental but usually the combination of both. There exists a distinctive pattern of Neurodevelopmental pattern characterized by cognitive, emotional and behavioral impairment in CHD survivors. Many school survivors of infant cardiac surgeries undergo unexplainable emotional disturbances which lead to the behavioral modification reflecting a negative aspect of life. Early screening and rehabilitation training as follow up procedure post operatively consequently result in improvement of positive approach as outcome in this high risk population.[1]

In early fetus the brain and heart develop simultaneously. The derangement of the fetal blood flow results in impaired blood flow to brain. In return impairing Brain growth and development. Medical and surgical procedure management has resulted in significant decrease in the mortality rate but causing a declined quality of life with poor development of cognitive, emotional and behavioral skills.

Stress is generally defined as the body's nonspecific response or reaction to demands made on it, or to disturbing events in the environment .It is a process by which we perceive and cope with environmental threats and challenges. Personal and environmental events that cause stress are known as stressors, Therefore, stress is simply defined as emotional disturbances or changes caused by stressors [2]. Chronic and excessive stress leads to physical, emotional and mental health problems and affects students academic achievement, personal and professional development .Therefore, early detection and intervention may prevent and minimize the exert effects of stress on the Children future. Stress on middle school students needs to be recognized, and strategies developed to improve it should be focused on both individual and situational factors.

Coping is a complex mental process by which a person deals with stress, solves problems, and makes decisions. It is an emotional, cognitive and behavioral response of a patient to an illness. Coping process involves at least two stages: confronting and managing with different aspects of illness or disability [3]. Since every children is a unique person, an emotional, cognitive and behavioral response can vary a lot and can occasionally be quite unpredictable .According to Folkman \& Lazarus coping strategies can be grouped into two general types; problem-focused and emotion-focused coping. Problem-focused coping is aimed at problem solving or doing something to alter the source of stress. Emotion-focused coping is aimed at reducing or managing the emotional distress that is associated with the situation. Although most stressors elicit both types of coping, problem-focused coping tends to predominate when people feel that something constructive can be done, whereas emotion-focused coping tends to predominate when people feel that the stressor is something that must be endured [4]

(C) The International Journal of Indian Psychology, ISSN 2348-5396 (e)| ISSN: 2349-3429 (p) | 88 


\section{The Effectiveness of Coping Strategy Training For Behavioural Modification among School Going Heart Defect Children after Surgery}

Effective and appropriate coping strategies may buffer the impact of newly encountered stressful situations on mental and physical health. Therefore, using coping strategies effectively and appropriately will help the children in improving their stress level. [4]

This study reveals the importance of Coping Strategy training post operatively in children with CHD .Middle School children with congenital heart disease adopt their illness as a part of their lives using their own knowledge and undergo unexplainable stress. The love and affection, sympathy attitude reflects in extreme pressure which make them feel different from their normal peer group, teacher -student relation and parental relation. However, most health providers tend to provide information about congenital heart disease mainly to the parents instead to the child, and many parents tend to be uncomfortable talking about the disease with their child. It is essential for the child to understand the ways in which they can cope up with stress as well as the degree of their knowledge to better explicate the process of adaptation to the illness. Hence the follow-up coping strategies demonstrate much higher resilience in children which able them to live quality life as normal children understanding self and situation to cope up.

\section{Aim:}

1. To study and compare coping strategy trained (CST) CHD middle school children and Coping Strategy untrained (CSUT) CHD children post operatively.

\section{Objectivity of the Study:}

1. To study the specific stressor in children with CHD.

2. To assess the effectiveness of coping strategy training postoperatively in middle school children.

\section{Procedure:}

This preliminary experimental study involving 20 middle school children aged 6-8years both male and female, who have undergone surgery for their congenital heart defect. Simple randomized sampling method was used in selecting children. The sample was divides into two groups ExperimentalGroup1: CST Coping Strategy trained, ControlGroup2: Control group CSUT Coping Strategy untrained.

Children and parents were educated about the nature and procedure of the study. A preview of the study and the importance was explained to the parent along with their children, and then they were enrolled in the study obtaining parental consent. All baseline assessment like demographic, socioeconomic, medical data was done individually for both groups. One of the appendix of the inventory was the identification of a specific stressor. The common specific stressor identified for both group was unexplainable emotion due to the difference in attitude (sympathized attitude) 
The Effectiveness of Coping Strategy Training For Behavioural Modification among School Going Heart Defect Children after Surgery

of teachers and class mates during rejoining school after a break of months after hospitalization. The specific stressor was noted in their respective questionnaire.

Investigator helps to fill in the questionnaire during face-to-face session with the children. Completion of the questionnaire was voluntary.

\section{Tool Used}

The following tabular representation shows the name of the tool; author and number of items.

\begin{tabular}{|c|c|c|c|}
\hline S.No. & Name of the Tool & Author & No of items \\
\hline 1. & $\begin{array}{l}\text { Coping Strategies Inventory (CSI) } \\
\text { Questionnaire designed to assess } \\
\text { coping thoughts and behaviors in } \\
\text { response to a specific stressor. }\end{array}$ & Davidl.Tobin’s & $\begin{array}{l}\text { 72-item self-report } \\
\text { The primary scale consist of } \\
\text { specific coping strategies } \\
\text { Children's use in response to } \\
\text { stressful events. } \\
\text { They are : } \\
\text { - } \quad \text { Problem Solving } \\
\text { - } \quad \text { Cognitive } \\
\text { Restructuring } \\
\text { - } \quad \text { Express Emotion } \\
\text { - } \quad \text { Social Support } \\
\text { - } \quad \text { Problem Avoidance } \\
\text { - } \quad \text { Wishful Thinking, } \\
\text { - } \quad \text { Self Critic, } \\
\text { - } \quad \text { Social With drawal, } \\
\text { Each consists of } 8 \text { questions. }\end{array}$ \\
\hline
\end{tabular}

The coping strategy training CST schedule including each program description, material requirement, set up , instruction to children and parents. All basic instruction was given. The session involved only children of Experimental group 1 and first few sessions were devoted to the introduction of the program. The children in the experimental group were given 15hours of coping Strategy after the surgery from the date the children starts the review of the cardiologist as outpatient before rejoining the school.

The effectiveness of coping strategy is accessed using the Coping Strategies Inventory(CSI) ,15 days after the children of both group rejoins school. It is a 72-item questionnaire designed to assess coping thoughts and behaviors in response to a specific stressor. The children taking the CSI were asked to respond to 72 questions in a 5-item Likert format. Respondents indicate each item to the extent they performed that particular coping response in dealing with the previously 
described situation (Specific Stressor) a. None =0; b. A Little =1; c. Some=2; d. Much=3; e. Very Much=4. The Subscales of the Coping Strategies Inventory was accessed using primary scale. The primary scales consist of specific coping strategies children use in response to stressful events. These include Problem Solving, Cognitive Restructuring, Express emotion, Social Support, Problem Avoidance, Wishful Thinking, Self Critism, Social With drawal, each specific coping strategy consists of 8 questions each. The time taken by the child for answering the questionnaire was around 1hour. The questionnaires were collected for both experimental group1 and control group 2

\section{Analysis:}

The data thus collected following the above design and procedure was interrupted using mean and standard deviation which was compared through independent $t$ test using SPSS.

\section{RESULT}

Table 1: Level of Coping among the Children in Both Groups

\begin{tabular}{|c|c|c|c|c|}
\hline \multirow{2}{*}{\multicolumn{2}{|c|}{ PRIMARY COPING SUB SCALE }} & \multicolumn{3}{|c|}{ LEVEL OF COPING } \\
\hline & & \multirow{2}{*}{\begin{tabular}{|l|} 
Inadequate \\
0
\end{tabular}} & \multirow{2}{*}{$\begin{array}{l}\begin{array}{l}\text { Moderately } \\
\text { Adequate }\end{array} \\
2\end{array}$} & \multirow{2}{*}{$\begin{array}{l}\text { Adequate } \\
8 \\
\end{array}$} \\
\hline \multirow[b]{2}{*}{ Problem Solving } & \begin{tabular}{|l|} 
Experimental- CST \\
\end{tabular} & & & \\
\hline & \begin{tabular}{|l|} 
Control- CSUT \\
\end{tabular} & 9 & 1 & 0 \\
\hline \multirow[b]{2}{*}{$\begin{array}{l}\text { Cognitive } \\
\text { Restructuring }\end{array}$} & Experimental- CST & 0 & 0 & 10 \\
\hline & Control- CSUT & 10 & 0 & 0 \\
\hline \multirow[b]{2}{*}{ Express Emotions } & Experimental- CST & 0 & 0 & 10 \\
\hline & Control- CSUT & 4 & 6 & 0 \\
\hline \multirow{2}{*}{ Social Support } & Experimental- CST & 0 & 0 & 10 \\
\hline & Control- CSUT & 10 & 0 & 0 \\
\hline \multirow[b]{2}{*}{ Problem Avoidance } & Experimental- CST & 0 & 0 & 10 \\
\hline & \begin{tabular}{|l|} 
Control- CSUT \\
\end{tabular} & 10 & 0 & 0 \\
\hline \multirow[b]{2}{*}{ Wishful Thinking } & \begin{tabular}{|l|} 
Experimental- CST \\
\end{tabular} & 0 & 0 & 10 \\
\hline & Control- CSUT & 5 & 4 & 1 \\
\hline \multirow[b]{2}{*}{ Self Criticism } & Experimental- CST & 0 & 0 & 10 \\
\hline & \begin{tabular}{|l|} 
Control- CSUT \\
\end{tabular} & 10 & 0 & 0 \\
\hline \multirow[b]{2}{*}{ Social Withdrawal } & Experimental- CST & 0 & 3 & 7 \\
\hline & \begin{tabular}{|l|} 
Control- CSUT \\
\end{tabular} & 8 & 2 & 0 \\
\hline
\end{tabular}

Table 1 explains the level of coping among the children in both groups, this table helps to understand the category, effectiveness and efficiency about the coping strategy training in middle school children with surgically corrected CHD. The score obtained in the questionnaire for each subtest is further converted into percentage and categorized depending on score listed below.

Score: $<50 \%$ - Inadequate level of Coping

$>50 \%-<75 \%$ - Moderately Adequate level of Coping

$>75 \%$-Adequate level of coping

(C) The International Journal of Indian Psychology, ISSN 2348-5396 (e)| ISSN: 2349-3429 (p) | 91 
The Effectiveness of Coping Strategy Training For Behavioural Modification among School Going Heart Defect Children after Surgery

Experimental Group 1- CST shows 100\% adequate in Cognitive Restructuring, Express Emotion, Social Support, Problem Avoidance, Wishful Thinking, Self Critics type of coping, $80 \%$ in problem solving and $70 \%$ in social withdrawal.

Control group 2: CSUT shows 0\% adequate in Cognitive Restructuring, Express Emotion, Social Support, Problem Avoidance, Self Critism type of coping, problem solving, social withdrawal and $10 \%$ adequate in wishful thinking.

Table 2: Comparison of Subtest of Primary Subscale from Coping Strategy Inventory between Experimentalgroup1 CST And Controlgroup2: Control Group Csut. $N=20$

\begin{tabular}{|l|l|l|l|}
\hline PRIMARY SUB SCALE & $\begin{array}{l}\text { Experimental group1 } \\
\text { CST } \\
(\text { Mean } \pm \text { SD) }\end{array}$ & $\begin{array}{l}\text { Control group2 } \\
\text { CSUT } \\
\text { (Mean } \pm \text { SD) }\end{array}$ & t value \\
\hline Problem Solving & $3.04 \pm 0.22$ & $1.13 \pm 0.19$ & $20.19^{*}$ \\
\hline Cognitive Restructuring & $3.13 \pm 0.17$ & $1.20 \pm 0.17$ & $29.55^{*}$ \\
\hline Express Emotion & $3.23 \pm 0.15$ & $1.30 \pm 0.22$ & $21.96^{*}$ \\
\hline Social Support & $3.38 \pm 0.21$ & $1.47 \pm 0.51$ & $10.98^{*}$ \\
\hline Problem Avoidance & $3.58 \pm 0.15$ & $0.93 \pm 0.24$ & $29.15^{*}$ \\
\hline Wishful Thinking & $3.37 \pm 0.27$ & $1.5 \pm 0.75$ & $7.22^{*}$ \\
\hline Self Critism & $3.31 \pm 0.15$ & $0.75 \pm 0.21$ & $31.10^{*}$ \\
\hline Social Withdrawal & $3.00 \pm 0.19$ & $1.16 \pm 0.27$ & $17.23^{*}$ \\
\hline
\end{tabular}

* P<0.01 : Highly Statistically Significant

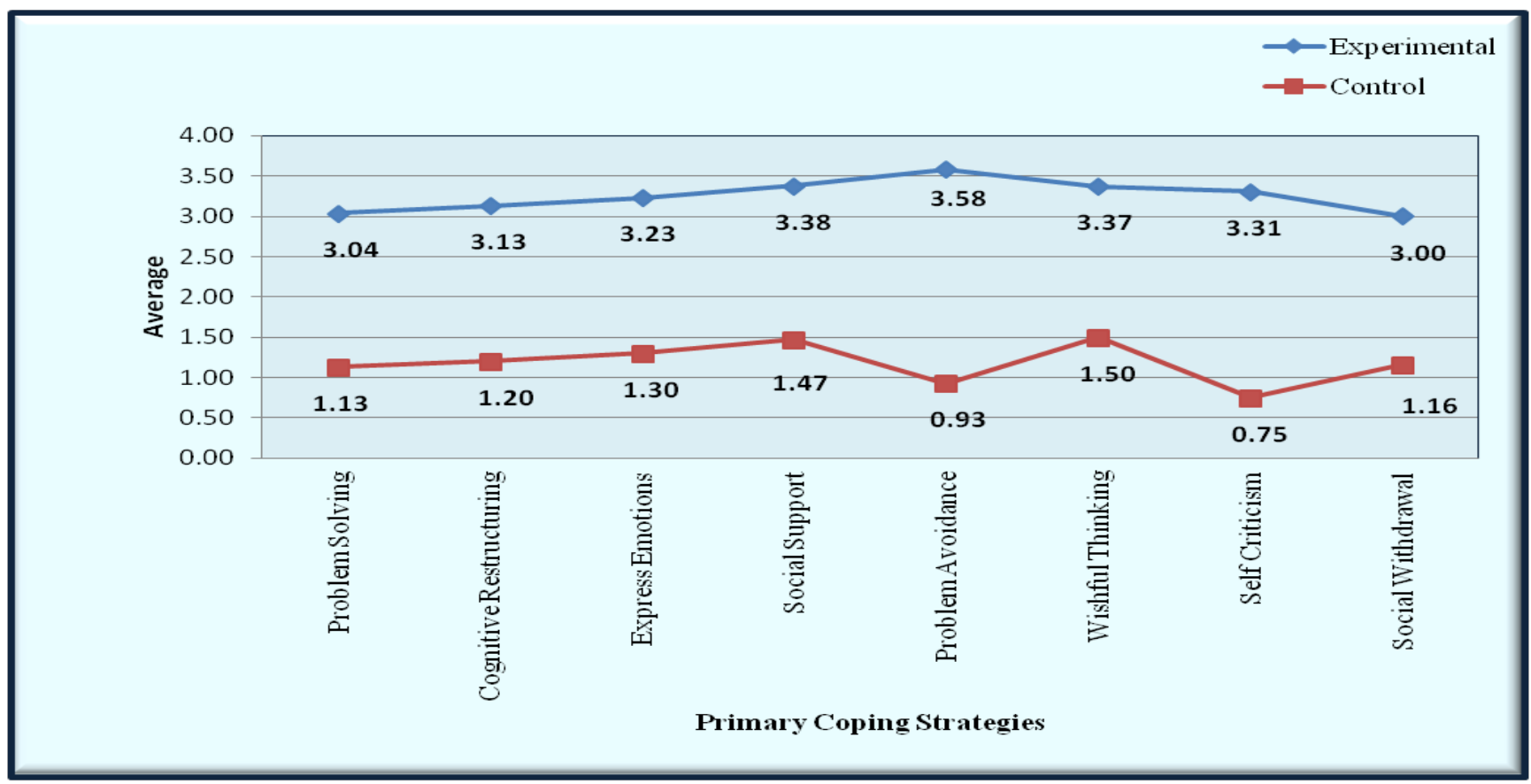

(c) The International Journal of Indian Psychology, ISSN 2348-5396 (e)| ISSN: 2349-3429 (p) | 92 
The Effectiveness of Coping Strategy Training For Behavioural Modification among School Going Heart Defect Children after Surgery

Table 2 shows the Comparative analysis of subtest of primary subscale from Coping Strategy inventory between ExperimentalGroup1 CST and ControlGroup2: CSUT .Sample size 20 subjects (Male 9 and Female 11)

It is observed that the obtained t values are highly significant for Problem Solving, Cognitive Restructuring, Express Emotion, Social Support, Problem Avoidance, Wishful Thinking, Self Critism, Social With drawal, at $\mathrm{P}<(0.01)$.

\section{DISCUSSION}

It is interesting to mention that, this prevalence of Specific stress during rejoining the school after surgery such as cardiac surgery develops unexplainable pressure inside middle child hood who is incapable of explaining their emotions. When these children are provided with coping strategy training by health care provider there is highly significant results in the way they approach situation and person around. There is a sound of positive attitude within the individual and others. This training gives the children an insight that there are people with similar defect and the extra care provided is not sympathizing but a strong support and guidance available from the society who includes family, school and peer. The control group -coping strategy untrained group was in evident with the above mentioned emotions and emotional struggle; they developed negative attitude of seeing everything from their own knowledge which made them to suffer unbearable pressure leading to hatred of self and loved people around them. ExperimentalGroup1 CST- was in contrast to control group and performed matured in action and words. They showed positive attitude and sense of sharing and caring after training. However, the result should be interpreted cautiously since the small sample size used in this study might not reflect the actual prevalence in the population. Therefore, further study with appropriate sample size and better study design should be conducted in the future to confirm this finding. The facts suggest that training children to have a healthy mindset with positive coping strategies will be beneficial [5-7].Coping strategies is defined as how a person react or response toward a stressor [7-11]. Effective and appropriate coping strategies may minimize the impact of encountered stressful situations on one's wellbeing [12].

\section{CONCLUSION}

Coping Strategy training can help the children to cope up their life with positive approach and live a quality life which is multidimensional fulfillment of life.

\section{Abbreviations:}

CHD- Congenital Heart Disease or Defect; CST- Coping Strategy trained; CSUT- Coping Strategy Untrained ;MSC- Middle school children. 
The Effectiveness of Coping Strategy Training For Behavioural Modification among School Going Heart Defect Children after Surgery

\section{Acknowledgments}

The author appreciates all those who participated in the study and helped to facilitate the research process.

\section{Conflict of Interests}

The author declared no conflict of interests.

\section{REFERENCE}

1. Scallan MJ (2003). Brain injury in children with congenital heart disease. Paediatic Anaesth.;13:284-93. [PubMed]

2. Muhamad Saiful Bahri Yusoff (2010) ;University Sains Malaysia Stress, Stressors And Coping Strategies Among Secondary School Students In A Malaysian Government Secondary School: Initial Findings ASEAN Journal of Psychiatry, Vol.11(2) July December 2010.

3. Lilijana Šprah and Mojca Šoštarič (2004). Psychosocial coping strategies in cancer patients Institute of Medical Sciences, Slovenian Academy of Science and Arts, Ljubljana, Slovenia; Radiol Oncol 2004; 38(1): 35-42.

4. Folkman S and Lazarus RS . An analysis of coping in a middleaged community sample. Journal of Health and Social Behavior, 1980: 21; 219-239

5. Shapiro SL, Shapiro DE and Schwartz GE (2000). Stress management in medical education: $a$ review of the literature. Acad Med, 75 (7): 748-759.

6. Muhamad SBY and Ahmad FAR (2010).Impact of the medical students' well-being in reducing medical students' stress level, ASEAN Journal of Psychiatry, Jan-June: 11 (1).

7. Muhamad SBY and Ahmad FAR(2009). Experiences from a medical students' well-being workshop, Medical Education Journal, 43 (11); 1108-1109

8. Rosenham DL, and Seligman ME. (1989) Abnormal psychology. 2nd ed. New York: Norton,.

9. Selye H(1974). Stress without distress. New York: Harper \& Row,.

10. Myers DG (2005). Stress and Health, in: Exploring Psychology. 6th ed. New York, Worth Publishers,

11. Lazarus RS.(1990) Theory-Based Stress Measurement, Psychology Inquiry; 1 (1): 3-13.Selye H. Stress without distress. New York: Harper \& Row, 1974.

12. Park CL and Adler NE, (2003). Coping styles as a predictor of health and well-being across the first year of medical school, Health Psychology; 22 (6): 627-631.

How to cite this article: M Jobson, R Subhashini (2016), The Effectiveness of Coping Strategy Training For Behavioural Modification among School Going Heart Defect Children after Surgery, International Journal of Indian Psychology, Volume 3, Issue 4, No. 64, ISSN 23485396 (e), ISSN: 2349-3429 (p), DIP: 18.01.123/20160304, ISBN: 978-1-365-32519-9 